\title{
Agentes, processos e conflitos na gestão territorial no Estado de Rondônia (Brasil)
}

\author{
Ricardo Gilson da Costa Silva \\ Universidade Federal de Rondônia (UNIR), Porto Velho, Brasil. \\ Email: rgilson@unir.br
}

\begin{abstract}
Resumo:Uma das questões geográficas derivadas do processo de modernização da agropecuária na Amazônia reside na demanda por novas áreas rurais, que atende tanto a expansão do capital agrário e agroindustrial, quanto à necessidade dos camponeses expropriados. A conversão de novas áreas para a agropecuária se torna uma problemática geográfica central, na medida em que o uso do território se coloca como condição contraditória para a reprodução dos grupos/ classes sociais envolvidos no processo. $\mathrm{O}$ artigo analisa a geografia que se configura na região do município de Porto Velho, localizada no norte do Estado de Rondônia (Brasil), onde o surgimento de frentes pioneiras resulta na ocupação de áreas públicas e, consequentemente, amplia-se a pressão sócio-territorial em Unidades de Conservação e Terras Indígenas. Assim, o ordenamento territorial efetivada no Zoneamento Socioeconômico e Ecológico de Rondônia sofre permanentes modificações, sendo confrontada pelos diversos agentes territoriais desejosos da construção de novos usos do território ${ }^{1}$.

Palavras-chaves: Rondônia, gestão do território, frentes pioneiras, geografia agrária.
\end{abstract}

\section{Agentes, procesos y conflictos en la gestión territorial en el estado de Rondônia (Brasil)}

Resumen: Una de las cuestiones geográficas derivadas del proceso de modernización de la agricultura en el Amazonas es la demanda de nuevas zonas rurales, tanto por la expansión del capital agrícola y agroindustrial, como por las necesidades de los campesinos expropiados. La conversión de nuevas áreas para la agricultura se convierte en un problema geográfico central, en la medida en que el uso de la tierra se pone como condición contradictoria para la reproducción de los grupos/ clases sociales involucradas en el proceso. El artículo analiza la geografía que se configura en la región del municipio de Porto Velho, situado al norte del Estado de Rondônia (Brasil), donde el surgimiento de frentes pioneros resultó en la ocupación de los espacios públicos y, consecuentemente, en la ampliación de la presión socioterritorial en Unidades de Conservación y Tierras Indígenas. De esta manera, el ordenamiento territorial efectuado en la Zonificación Socioeconómica y Ecológica de Rondônia sufre modificaciones permanentes, siendo confrontada por los diferentes agentes territoriales deseosos de la construcción de nuevos usos del territorio. fía agraria.

Palabras clave: Rondônia, gestión del territorio, frentes pioneros, geogra- 


\title{
Agents, processes and conflict in the territorial management in Rondônia state (Brazil)
}

\begin{abstract}
One geographical issue that came from the modernization process in Amazon's cattle raising lands lies on the demand for new rural areas, serving both agricultural and agro-industrial capital expansion, and on the other way, the expropriated peasants necessities. The conversion of new areas on cattle farms have become a central problem for geography, as far as the territory use functions as a contradictory condition to social groups/classes reproduction, as they are linked in this process. The article analyzes the geography that is configured in Porto Velho municipality region, located in the north part of Rondônia state (Brazil), where the emergence of pioneer fronts resulted in private occupation on public areas and consequently, social and territorial pressure expanded over Conservancy Land Areas and Indigenous Territoy. Thus, the Socioeconomic and Ecological Spatial Zoning planned to occur in Rondônia state, suffers permanent modifications, being confronted by the multiple territorial agents, expecting the formulation of new territory use.
\end{abstract} geography.

Keywords: Rondônia, territory management, pioneer fronts, agrarian

\section{Introdução}

Uma das questões geográficas postas pelo processo de modernização da agropecuária na Amazônia reside no crescimento da demanda por novas áreas rurais, que objetiva tanto atender a expansão do agronegócio, quanto à necessidade dos camponeses expropriados. A conversão de novas áreas para a produção agrícola se torna uma problemática geográfica central, na medida em que o uso do território se coloca como condição para a reprodução dos grupos sociais e do capital agrário/industrial, opondo, conflitivamente, as comunidades tradicionais amazônicas. Esse é o quadro geográfico que assume relevo nas últimas décadas na região de Porto Velho, localizada no norte do Estado de Rondônia, na divisa com os Estados do Amazonas e Acre (Amazônia brasileira), especificamente na vila de União Bandeirantes, objeto desse texto.

Para a realização dessa pesquisa adotamos os seguintes procedimentos metodológicos: revisão bibliográfica, análise de documentos e relatórios de instituições públicas e particulares relacionados à temática e área de pesquisa, consulta à legislação de gestão territorial (fontes secundárias); pesquisa de campo em União Bandeirantes (Figura 2), onde dialogamos com comerciantes e camponeses migrantes, visando compreender as variáveis que explicam a formação do povoado, assim como, as incongruências em termos de ordenamento do território (fontes primárias). Por fim, utilizamos recursos cartográficos, o qual foi possível sistematizar as diversas lógicas do uso do território.

As dinâmicas territoriais locais apontam para a pressão política, 
econômica e social em áreas protegidas, como as Terras Indígenas e Unidades de Conservação, assim como, a ocupação de terras ainda sem função econômica, normalmente áreas públicas ocupadas e disputadas por diversos grupos sociais e econômicos (camponeses, madeireiros, pecuaristas, grileiros de terras, dentre outros). Considerada uma das áreas mais preservadas no espaço rural rondoniense, o processo de ocupação desordenado do espaço agrário de Porto Velho é resultado das expropriações do campesinato, principalmente da região central de Rondônia, cuja migração para novas terras passou a ser apoiada por grupos políticos do setor da agropecuária e do agronegócio, forçando novos usos do território. Assim, gerando conflitos sócioterritoriais com as comunidades tradicionais que já ocupavam essas terras há décadas. No plano da gestão do território, a política estadual de ordenamento territorial (Zoneamento Socioeconômico e Ecológico) sofre permanentes modificações, sendo confrontada pelos diversos agentes territoriais desejosos da construção de novos territórios.

Como resultado, temos a incorporação de novos espaços que ainda não haviam sido objetos dos fluxos sociais e econômicos, manifestado na substituição da floresta pela agropecuária, na exploração madeireira, nos projetos de assentamentos rurais e nas grilagens de terras. Em função desse movimento espacial as tensões sócioterritoriais aumentaram substancialmente no agrorondoniense, apontando para uma nova agenda territorial como condição para a reprodução de diversos grupos sociais. Nessa perspectiva, o uso do território assume relevância política central opondo os agentes públicos, sociais e econômicos na construção política de seus projetos, no qual o território expressa as contradições sociais que se cristalizam em Rondônia.

\section{Metamorfoses do espaço rondoniense: políticas territoriais, migração e agropecuária}

A ciência geográfica conceitua políticas territoriais como "toda e qualquer atividade estatal que implique, simultaneamente, 'uma dada concepção do espaço nacional', uma estratégia de intervenção ao nível da estrutura territorial e, por fim, mecanismos concretos que sejam capazes de viabilizar essas políticas” (Costa, 1991: 13). As políticas territoriais abordam ações estatais correspondentes, dentre elas: urbanização, regionalização, rede de transportes, gestão ambiental e territorial, colonização, políticas agrícolas e agrárias que transformam e organizam o espaço objeto de intervenção, o que as qualifica como políticas que produzem espaço(Moraes, 1994). A natureza das políticas territoriais expressa sempre uma imagem do espaço a ser produzido, conceitos e visões sociais e ideológicas do Estado - o principal agente territorial - e dos grupos sociais e econômicos que atuam no âmbito dessas ações, ora propondo intervenções, ora se colocando contra essas políticas (Silva, 2012). Contraditoriamente, ao produzir espaço se exclui 
setores ou segmentos da sociedade que viviam e vivem no espaço alterado, causando processos de fragmentação do espaço e/ou de (des)territorialização.

Nessa perspectiva, toda ação estatal que objetiva a produção de determinado espaço dialeticamente produz contradições territoriais, acarretando uma série de situações geográficas até então estranhas ao cotidiano modificado. Desse modo, algumas questões emergem no conjunto social como problemáticas eminentemente territoriais derivadas das transformações objetivamente operadas pelo Estado, somadas as outras situações não previstas que terminam por permear o meio geográfico, instaurando processos estranhos ao espaço vivido. O meio geográfico é modificado/produzido pelas ações sociais, pelas tramas da história humana que instituem suas grafias no espaço. O Estado é um dos agentes que formula e cria suas inscritas no espaço modificado, que é sempre um espaço projetado, um espaço teleológicamente pensado e a ação - no caso, as políticas públicas - concretizam esses projetos.

Essas reflexões nos remetem a formular que a questão ambiental e territorial surge em Rondônia na década de 1970 , a partir de duas importantes políticas públicas territoriais orientadas pelo Estado que delineou a formação socioespacial dessa região da Amazônia ocidental, quais sejam: a colonização agrícola e a construção de estradas - a rede rodoviária (Thery, [1974] 2012; Silva, 2012, 2014). A colonização agrícola gestada pelo governo federal, através do INCRA ${ }^{2}$, proporcionou acesso à terra a milhares de camponeses migrantes de todas as regiões do país. Mesmo considerando as contradiçõ̃es no processo de assentamento rural realizado em Rondônia, dentre elas, a falta de estrutura adequada para responder as demandas camponesas, o governo assegurou e partilhou a terra para milhares de famílias, e os dados fundiários do estado de Rondônia expressam a magnitude desse processo geográfico. Segundo as informações do Censo Agropecuário (IBGE, 2006), Rondônia passou de 7.082 estabelecimentos agropecuários em 1970, para 25.483 unidades já em 1975, e em 1980 as unidades representavam 48.371 estabelecimentos, indicando crescimento de 583\% para o período de dez anos (Gráfico 1). Na década de 1980, a propaganda governamental e a expectativa positiva dos camponeses em relação à posse da terra ampliaram o fluxo migratório, algo que obrigou o INCRA a quase dobrar a distribuição de terras, crescendo para 80.615 estabelecimentos agropecuários (1985), e ampliando para 87.078 unidades em 2006. 


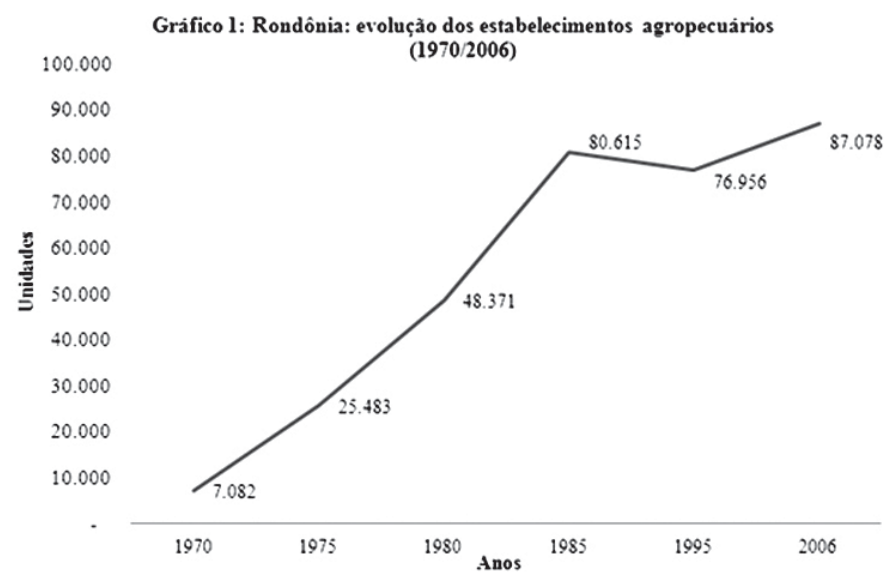

Fonte: IBGE, 2006. Censo Agropecuário.

Organização: Autor.

Acrescenta-se ao conjunto de informações fundiárias o crescimento da população urbana e rural, esta última distribuída em dezenas de assentamentos rurais organizados no âmbito dos projetos de colonização pública. No período de 1970 a 2007, o INCRA implantou 155 projetos de assentamento rural, inclusos nas tipologias de colonização oficial, assentamento rápido e reforma agrária, correspondendo a uma área de 5.809.662 de hectares para atender 77.503 famílias, em geral, camponesas, as quais $67 \%$ foram assentadas no período de 1970/1994, ou seja, no período de maior atuação do INCRA na gestão do território em Rondônia (INCRA 2013; Silva 2012). Ficam evidentes as transformações do/no espaço regional rondoniense com o processo de colonização agrícola (Figura 1).

Figura 1: Início da colonização em Rondônia (1974). Vista da Vila de Rondônia, hoje cidade de Ji-Paraná, a segunda na hierarquia urbana rondoniense.

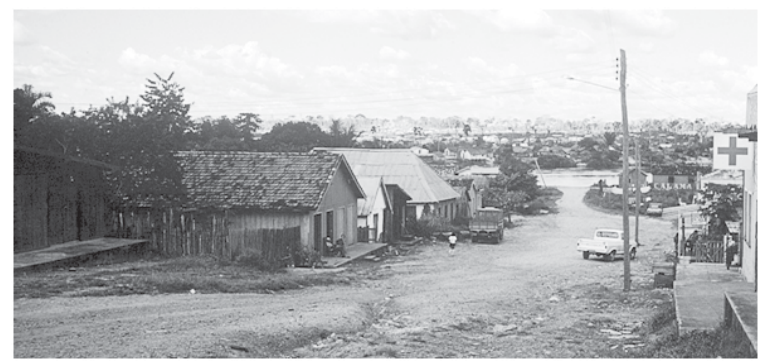

Foto: Hervé Thery (1974) 
Anteriormente, o espaço foi modificado pelo extrativismo vegetal e mineral, atividades produtivas que empregavam parte significativa da população e que dinamizavam o espaço social, delineando seus aspectos principais. Os produtos mais importantes da geografia econômica eram: borracha, castanha do Brasil, pescado e o minério (cassiterita). Todavia, a extração desses produtos pouco modificou o meio geográfico, permanecendo a massa florestal como o elemento mais relevante da paisagem rural. A colonização agrícola implantada como política territorial instaura outro modelo de ocupação e uso do espaço, agora ancorado na agropecuária, no agronegócio, na agroindústria, na formação e expansão da rede urbana e rodoviária, como processos motores das dinâmicas territoriais (Thery [1974], 2012; Silva, 2012; 2014).

O crescimento da agropecuária e da exploração madeireira não somente mercantilizou a natureza no conjunto da sociedade, como em termos de representações sociais, a transformou de patamar, (re)significandoa como valor de troca, portanto, como mercadoria e ativo na economia regional emergente. Associada a essas transformações outros fenômenos foram agregados ao espaço metamorfoseado, dentre os quais se destacam a questão do desmatamento ou desflorestamento e os conflitos territoriais, processos que enquanto problemática geográfica, até a década de 1960, no conjunto social era quase que inexistente ${ }^{3}$. Qualificamos como fenômenos geográficos por representarem a inscrição espacial da sociedade emergente, dotando o meio geográfico de formas-conteúdo (Santos, 1996) da colonização, uma sociedade que tinha e ainda encerra na destruição da natureza um dos processos pilares de sua reprodução social. A questão ambiental emerge desse processo e os conflitos territoriais dizem respeito às disputas de territórios que se realizam através da apropriação simbólica ou da dominação da sociedade sobre o espaço, o que tem gerado processos concomitantes de des-re-territorialização (Haesbaert, 2004).

\section{Políticas territoriais e gestão do território: a experiência dos Zoneamentos}

Consideramos a gestão do território como prática política que visa concretizar um projeto de espaço, organizar e produzir um espaço determinado. É por excelência um exercício político do Estado em sua ação como agente territorial que objetiva modular o espaço objeto de intervenção (Raffestin, 1993). Outros atores/agentes também praticam a gestão do território, mas com escalas geográficas e instrumentos jurídicos normativos diferentes. Becker (1991) compreende a gestão do território como uma prática estratégica, científico-tecnológica do poder no espaço, que exige um conjunto de normas e instrumentos para modificar e concretizar o ordenamento do território.

As dinâmicas territoriais produzidas pela sociedade impõem ao Estado ordenar os processos sociais que desorganizam as formas pretéritas de uso do espaço e propugnam outras lógicas e sentidos ao espaço transfor- 
mado. O conceito de território expressa sempre um “determinado uso do espaço, consubstanciado em mecanismos de apropriação, de controle e de defesa por agentes públicos e privados, através dos quais se viabilizam práticas de poder” (Davidovich, 1991: 8). Ou seja, o território manifesta a espacialização das práticas políticas operadas pelos diversos agentes/atores, grupos sociais e classes que projetam e reivindicam uma forma de uso político do espaço, sejam as práticas de apropriação simbólica ou de dominação econômica do espaço, expressando a dimensão política do espaço disputado (Haesbaert, 2004). A gestão do território significa pactuar socialmente o uso do espaço, um ato que envolve temporalidades e espacialidades diversas e contraditórias em permanente devir, sempre pressionadas pelas práxis e práticas espaciais dos grupos políticos que trabalham e desenvolvem certas ideias, visões e projetos de território.

As práticas espaciais gestadas pela sociedade rondoniense, produto do processo de migração e colonização agrícola em relação ao meio natural, promoveram modificações através das formas emergentes de valorização do espaço. Como já afirmamos, o espaço rondoniense foi transformado pelo avanço da agropecuária, extração madeireira e expansão da rede rodoviária. Esses processos ampliaram o raio de ação da sociedade envolvente, majoritariamente formada por colonos e migrantes sulistas, que viam na natureza a necessária transformação em espaço produtivo agrícola, significando a metamorfose do meio geográfico natural para o meio técnico(Santos, 1996), este povoado por lógicas de apropriação capitalista do espaço.

Ao protagonismo do Estado (Governo Federal), o principal agente da transformação espacial em Rondônia, acrescenta-se o papel que o Banco Mundial (BM) assumiu - através de empréstimos financeiros - na formulação de políticas públicas de natureza territorial que configuraram o espaço geográfico rondoniense. O primeiro programa apoiado pelo BM foi o POLONOROESTE ${ }^{4}$, executado na década de 1980. Inicialmente, o programa estabeleceu como meta a pavimentação da rodovia BR-364, mas em função das demandas ampliadas pelo fluxo migratório e a distribuição de terras, incorporou melhorias nas estradas (secundárias e vicinais) que permitiu acesso às propriedades dos colonos, consolidação e criação de novos projetos de assentamentos, infraestrutura de saúde, educação, assistência técnica, regularização fundiária e apoio às populações indígenas, dentre outras ações. A principal meta, sem dúvida, foi a pavimentação da rodovia BR-364 (Cuiabá/Porto Velho, numa distância de 1.500 km), que favoreceu a integração com os mercados do Sudeste e Sul do Brasil e permitiu aos migrantes dessas regiões e do Nordeste chegarem à Rondônia e lutarem por terras. Na ótica geoeconômica, a abertura da estrada proporcionou maior fluxo de mercadorias, ampliando o espaço econômico sob a influência de São Paulo. Como consequência, a produção rondoniense passou a gravitar mais com a Região Concentrada ${ }^{5}$, fraturando a hierarquia urbana regional até então hegemonizada por Manaus.

A produção agrícola, o crescimento da pecuária e a extração madeira formaram os principais produtos do espaço produzido, servindo de alicerce 
para a sociabilidade capitalista no interior da floresta amazônica. O resultado foi o desmatamento exponencial que se desenhou na paisagem regional, somado aos crescentes conflitos territoriais que opunham indígenas, seringueiros, colonos, fazendeiros, mineradoras, empresas colonizadoras e o Estado - este representado basicamente através do IBDF/IBAMA, INCRA e FUNAI ${ }^{6}$. O cenário de destruição e conflitos territoriais alçou escalas nacional e internacional e as pressões das ONGs nacional e internacional fizeram com que o BM suspendesse, ainda que temporariamente, o repasse de recursos financeiros, obrigando o Governo Brasileiro a ajustar a execução do programa para incorporar as questões ambientais e as demandas das populações tradicionais (indígenas e seringueiros, principalmente). A concepção política do POLONOROESTE apontava para a formação de um espaço regional desenvolvimentista, vinculado à intensa exploração dos recursos naturais na ótica da ocupação capitalista. Como resultado, o processo social e geográfico produziu a negação do espaço natural - do meio natural - e da sociedade extrativista, transformando a Amazônia e, particularmente o espaço rondoniense, em um tipo de economia de fronteira, onde a dilapidação da natureza e sua rápida mercantilização se tornavam o motor das metamorfoses do espaço habitado pela sociedade migrante (Becker, 1991; Silva, 2012; 2014).

As taxas de desmatamento/desflorestamento se mostraram alarmantes, transformando-se no principal impacto ambiental do espaço rondoniense, resultado da inserção da região na economia brasileira sob o domínio das atividades agropecuárias e da extração madeireira. Como consequência, nos primeiros anos da colonização (1978), Rondônia apresentava uma área desflorestada de $4.200 \mathrm{Km}^{2}$, em 1991 esse dado era de $34.600 \mathrm{Km}^{2}$ e alcançou $80.243 \mathrm{Km}^{2}$ em 2010, representando 33,77\% da área territorial do Estado (Gráfico 2). O modelo de assentamento rural reconhecia o desmatamento como trabalho concretizado na terra, como "benfeitorias" que indicava ao INCRA o tipo de uso que se fazia no espaço agrário. Por sua vez, a ocupação desordenada se constituía em verdadeiras frentes pioneiras intra-estadual, abrindo novos caminhos na floresta e atingindo áreas ainda pouco pressionadas pela expansão agrícola, madeireira e de grilagem de terras.

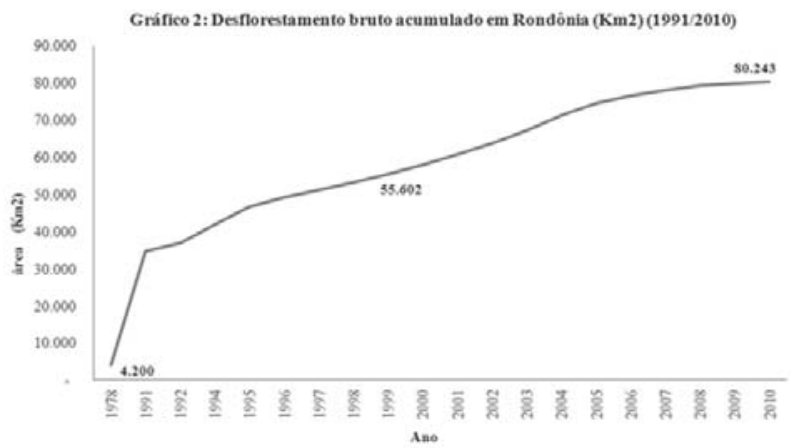

Fonte: IBGE. Série Histórica e Estatística, oriundas do PRODES/INPE. Organização: Autor. 
As consequências da transformação do espaço natural(meio natural ou pré-técnico) para o espaço da agropecuária (meio técnico) obrigou o Governo de Rondônia ${ }^{7}$ e o BM a pactuarem um novo financiamento visando conter o avanço do desmatamento, proteger áreas relevantes para a biodiversidade e implantar políticas setoriais voltadas para o desenvolvimento sustentável. O Plano Agropecuário e Florestal de Rondônia (PLANAFLORO) foi a resposta político-institucional à degradação ambiental e aos impactos territoriais resultantes da colonização, do avanço do desmatamento e das formas predatórias da utilização dos recursos da natureza. O produto principal consistiu na elaboração do Zoneamento SócioEconômico-Ecológico (ZSEE), tornando-se um instrumento inovador de planejamento regional e de gestão e ordenamento do território (RONDÔNIA, 2010). No POLONOROESTE, os agentes territoriais foram o Governo Federal (GF) e o BM, sem outras participações e mediações sociais. No PLANAFLORO, o recém Governo de Rondônia (GR) negociava com o BM, com a mediação do GF e sob forte pressão da sociedade civil organizada por meio de sindicatos, movimentos sociais e, principalmente, das Organizações Não Governamentais (ONGs).

Cabe destacar que o PLANAFLORO incluiu medidas institucionais visando construir um conjunto de mudanças que direcionassem a economia regional e o uso do espaço para o que se convencionou chamar de desenvolvimento sustentável. Além do ZSEE, as titulações de terras deveriam ocorrer concomitante à redução do desmatamento, seguido de práticas de regularização fundiária e incentivo à sustentabilidade ambiental. A adoção de políticas públicas para estudar, demarcar e proteger as áreas indígenas constou como uma das medidas aplicadas para controlar o rápido processo de transformação da natureza em madeira e pastagens (FORUM, 1997).

Para os formuladores da proposta de ZSEE para a Amazônia Legal, o zoneamento como instrumento de gestão e regulação do uso do território deveria ser executado seguindo três princípios básicos:

“1) a eficácia, referente à nova racionalidade de poupança de recursos e incorporação de informação e tecnologia nos produtos e processos; 2) a valorização da diferença, referente a identificação e potencialização das vantagens competitivas de cada território; 3) a descentralização, constituindo nova forma de governo em parceria, que identificamos como gestão do território, expressão da nova relação público-privada” (Becker y Egler, 1997: 5).

Na perspectiva institucional do Governo de Rondônia,

“o zoneamento é um instrumento técnico e político do planejamento das diferenças, segundo critérios de sustentabilidade, de absorção de conflitos, e de temporalidade, que lhe atribui caráter de processo dinâmico, que deve ser periodicamente revisto e atualizado, capaz de agilizar a passagem para o novo padrão de desenvolvimento. $\mathrm{O}$ zoneamento, portanto, não é um fim em si, nem mera divisão física, e 
tampouco visa criar zonas homogêneas e estáticas cristalizadas em mapas” (RONDÔNIA, 2010: 7).

A $1^{\mathrm{a}}$ (primeira) Aproximação do ZSEE de Rondônia (PAZ) foi concluído em 1988 e publicado em $1991^{8}$, na escala 1:1.000.000, elaborado pela equipe técnica do GR com apoio da FAO/Banco Mundial. Como resultado, elaborou-se um mapa dividindo o espaço rondoniense em seis zonas, com diferentes diretrizes para o uso da terra, conservação e proteção ambiental (Quadro 1). A metodologia adotada consistiu no levantamento sistemático de dados sobre o meio físico (dados do RADAMBRASIL e da Embrapa/SNCLS, por exemplo), utilizando imagens de sensoriamento remoto (LANDSAT-TM) e os mapas da situação fundiária de Rondônia. Buscou-se compatibilizar o espaço agrário decorrente da colonização em áreas homogêneas, destinando outras áreas para atividades produtivos sustentáveis, conservação e proteção ambiental e das comunidades amazônicas tradicionais que atualmente se conceitua como povos da floresta (indígenas, ribeirinhos, seringueiros, pescadores artesanais, quilombolas, dentre outros).

\section{Quadro 1: Divisão territorial de acordo com a 1ª Aproximação do Zoneamento de Rondônia (1988)}

\begin{tabular}{|c|l|l|c|c|}
\hline Zona & \multicolumn{1}{|c|}{ Destinação } & \multicolumn{1}{|c|}{ Finalidade } & Área (ha) & (\%) \\
\hline 1 & $\begin{array}{l}\text { Intensificação da } \\
\text { Exploração Agropecuária }\end{array}$ & $\begin{array}{l}\text { Ordenamento e recuperação das atividades agrícolas, } \\
\text { pecuárias e agroflorestais }\end{array}$ & 6.195 .000 & 28,0 \\
\hline 2 & $\begin{array}{l}\text { Pequenos produtores em } \\
\text { coletividade }\end{array}$ & $\begin{array}{l}\text { Recuperação e desenvolvimento da atividade } \\
\text { agropecuária e de agricultura consorciada com } \\
\text { culturas permanentes }\end{array}$ & 3.015 .000 & 13,6 \\
\hline 3 & Ribeirinha & $\begin{array}{l}\text { Aproveitamento de várzeas e terras firmes marginais } \\
\text { aos rios, desenvolvendo atividades agroflorestais e } \\
\text { pesqueiras }\end{array}$ & 589.000 & 2,7 \\
\hline 4 & Extrativista & $\begin{array}{l}\text { Ordenamento e desenvolvimento do extrativismo } \\
\text { vegetal de castanha, gomas, óleos, frutos e raízes } \\
\text { exploráveis }\end{array}$ & 3.500 .000 & 15,8 \\
\hline 5 & Manejo Florestal & $\begin{array}{l}\text { Importante potencial madeireiro para extração em } \\
\text { escala comercial }\end{array}$ & 2.435 .000 & 11,0 \\
\hline 6 & Conservação e Preservação & $\begin{array}{l}\text { Garantir a manutenção dos ecossistemas e o } \\
\text { equilibrio ecológico }\end{array}$ & 6.400 .000 & 28,9 \\
\hline
\end{tabular}

Fonte: RONDÔNIA (2010)

O mapa da primeira aproximação indicava o uso do espaço visando orientar as políticas públicas e os processos de ocupação das terras em Rondônia. Propunha a gestão social do espaço, um mosaico de potencialidades econômicas combinando formas diferenciadas de utilização do território. Contudo, as disputas políticas das elites locais somadas a não publicidade, a não participação e o não compartilhamento dos resultados do zoneamento no conjunto da sociedade fizeram com que uma série de críticas fossem apontadas ao resultado do trabalho, principalmente pelos movimentos sociais ${ }^{9}$, das quais se destacam a visão emi- 
nentemente tecnocrática (portanto, sem participação social) do Zoneamento e a proposição de áreas destinadas à proteção e preservação ambiental com ocupação e titulação de terras anteriormente definidas, ou seja, áreas que haviam sido objeto de ocupação agropecuária e tituladas pelo INCRA.

Na parte metodológica, os trabalhos de campo foram poucos e inexistentes em algumas das sub-regiões de Rondônia. Algumas das áreas demarcadas e/ou indicadas como Unidade de Conservação e outras ajustadas aos limites territoriais das Terras Indígenas já eram objeto de ocupação, ou seja, foram criadas com famílias habitando essas terras. Dessa forma, surgiram tensionamentos entre os grupos sociais que reivindicam a territorialidade dessas áreas, opondo-se as populações tradicionais e os segmentos da sociedade emergentes da migração e colonização agrícola, cristalizando a fragilidade da política pública de ordenamento territorial e da própria legitimidade do Estado.

A $2^{\text {a }}$ (segunda) aproximação do ZSEE (SAZ) começou a ser discutida no início de 1990, no âmbito do PLANAFLORO ${ }^{10}$. As críticas apontadas pelas entidades da sociedade civil organizada indicavam que a participação social e formas de co-gestão das políticas públicas eram necessárias para se atingir os objetivos centrais do Zoneamento, quais sejam, como um instrumento de gestão do território para racionalizar o espaço na perspectiva do desenvolvimento sustentável para a Amazônia brasileira. A liberação dos recursos financeiros iniciou em 1993, mas a contratação da empresa para a execução da SAZ somente foi efetivada em 1996. Dentre outros fatores para o atraso contribuiu significativamente a desorganização governamental, e resultou na problemática licitação do consórcio internacional para execução dos serviços ${ }^{11}$.

A participação dos agentes territoriais se fez presente nos trabalhos da SAZ. Se o GR controlava os instrumentos legais e consultivos para implementar a SAZ, o BM financiava e impunha exigências para fazer o GR cumprir as cláusulas contratuais do financiamento do PLANAFLORO. A sociedade civil organizada no âmbito do Fórum das Organizações Não Governamentais (Fórum das Ong’s), reunia diversos segmentos do campo e da floresta, propunham e denunciavam os desvios de finalidade da proposta do Zoneamento, sobretudo, apontavam as incongruências entre os órgãos estaduais (SEDAM, ITERON) e os federais (INCRA, FUNAI, IBAMA) ${ }^{12}$, relativo à destinação de terras para assentamentos rurais em áreas de Unidades de Conservação e Terras Indígenas, ou os estímulos feitos pelos agentes públicos em orientar novas ocupações, fazendo avançar as frentes madeireiras e agropecuárias. 


\section{Mapa 1: Rondônia - 2a aproximação do Zoneamento Sócio-Ecológico-Econômico (2000)}

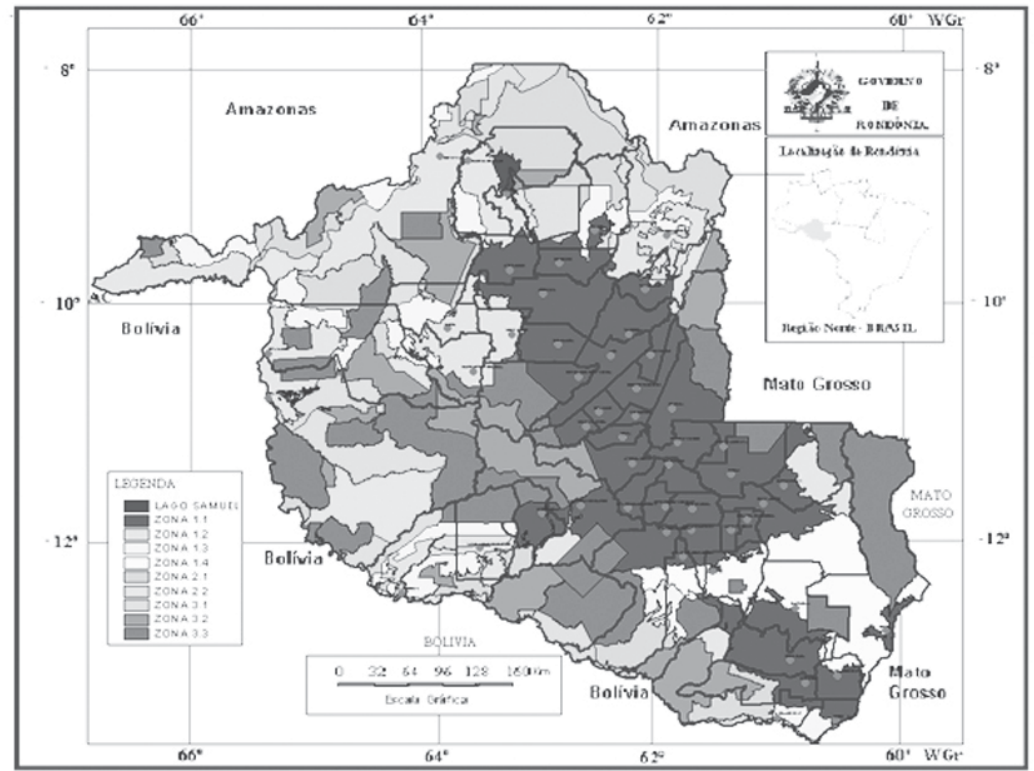

Fonte: Rondônia (2010).

O resultado da $\mathrm{SAZ}^{13}$ foi a proposição de um mapa (Mapa 1) com três grandes zonas (RONDÔNIA, 2010):

- Zona 1: “áreas de uso agropecuário e florestal”, com 120.310,48 $\mathrm{km}^{2}$, equivalentes a 50,45\% da área total do Estado, divididas em quatro sub-zonas, conforme as potencialidades de solos e outros recursos naturais, situação de ocupação;

- Zona 2: “áreas de uso especial”: abrangendo 34.834,42 km², equivalentes a 14,60 \% da área total do Estado, destinada à conservação dos recursos naturais, passíveis de uso sob manejo sustentável;

- Zona 3: “áreas institucionais”, totalizando 83.368 km² (34,95\% do Estado) compostas de UCs de Uso Sustentável (sub-zona 3.1), UCs de Proteção Integral (sub-zona 3.2) e Terras Indígenas (sub-zona 3.3).

O uso do território foi ajustado em três zonas que indicavam as principais dinâmicas territoriais de ocupação do espaço rondoniense. As áreas destinadas ao avanço e consolidação das atividades produtivas agrí- 
colas e ao uso florestal representava 50,45\% do Estado de Rondônia. Em contraste, as áreas de preservação e conservação ambiental qualificadas de Unidades de Conservação e as Terras Indígenas correspondiam a quase $35 \%$ do espaço territorial.

Concomitante a elaboração do SAZ, o avanço da extração madeireira e da agropecuária se consolidava como mecanismo econômico de reprodução social, o que a colocava em franca contradição com as políticas públicas de sustentabilidade ambiental. Nesse sentido, o ZSEE sempre foi questionado pelos diversos grupos sociais e econômicos, ou seja, os agentes territoriais que de fato modificam as configurações geográficas locais em função da proeminência agropecuária que se já se espacializava em Rondônia.

Nesse sentido, a análise do GTA-RO cristaliza as contradições do processo geográfico concretizado na elaboração da SAZ:

“Adotou-se uma política de legitimação de ocupações irregulares e ilegais, impulsionadas por políticas contraditórias e a omissão generalizada de órgãos ambientais.[...] Dentre os impactos das diversas iniciativas de redução e supressão de UCs estaduais entre 1995 a 2000, destacam-se: a redução de 1.055 .000 para 95,3 mil hectares (89\%) na área da Resex Rio Preto-Jacundá; redução de 298 mil hectares (31,9\%) na área total dos parques estaduais, com a supressão total de três deles (Serra dos Parecis, Roosevelt, Candeias); e supressão total de oito Florestas Estaduais de Rendimento Sustentado -Fers (Rio Abunã, Rio Madeira “C”, Rio Mequens, Rio São Domingos, Rio Roosevelt, Rio Vermelho “A”, “B’e “D”), com um total de 1.141.819 hectares, representando $77 \%$ da área total originalmente criada. Além disso, a Fers Rio Vermelho “C”, localizada na área de influência prevista para a hidrelétrica de Santo Antônio, foi drasticamente reduzida pela Lei Complementar no. 233/00, de 20.215 para 4.050 hectares”. (GTA/RO, 2008: 16-17)

A proposição de dois estudos ( $1^{\mathrm{a}}$ e $2^{\mathrm{a}}$ aproximação do ZSEE) para produzir a política estadual de ordenamento territorial em Rondônia, materializadas nos Zoneamentos, sinalizou dois processos contraditórios na produção do espaço regional rondoniense: a política de gestão do território, que objetivava a sustentabilidade ambiental, encontrava forte resistência política frente à necessidade social de reprodução do capital.

Em geral, as ações do Governo de Rondônia que visavam normatizar o ordenamento territorial sempre encontraram oposição dos agentes públicos ou da classe política (prefeitos, vereadores, deputados estaduais, deputados federais, senadores e, mesmo, setores do governo estadual) em aceitar o ZSEE como instrumento necessário para a gestão sustentável do espaço rural. A cultura da migração e as articulações políticas de diversos grupos sociais e dos setores do capital no campo, mesmo considerando suas contradições internas, inegavelmente se consolidou num poderoso grupo político ou um bloco político-territorial que, desde 1994, hegemoniza 
a política estadual, sempre pautada no crescimento econômico dos setores da agropecuária, agronegócio e madeireiros, articulados com os setores da agroindustrialização. Nessa ótica, as áreas destinadas à preservação e à conservação ambiental (Unidades de Conservação) e as áreas dos povos da floresta (indígenas, quilombolas, seringueiros, principalmente) são constantemente pressionadas pelas frentes madeireiras e agropecuárias que praticam o desmatamento, o roubo de madeira e, por fim, a grilagem de terras.

A questão que se assenta é que as representações sociais do espaço elaboradas pela sociedade emergente do processo de colonização agrícola foram sempre a de se produzir um espaço ancorado na mercantilização da terra e de seus produtos na ótica da reprodução do capital. O POLONOROESTE alimentou estruturalmente a geografia humana resultado da migração, sobretudo, através da abertura e expansão rodoviária, colocando-a como forte eixo de ocupação dos espaços naturais, dado que a imagem do território, sua representação social em termos de projetos políticos da sociedade fruto da migração, baseavase na exploração agropecuária, portanto, a socialização da natureza, na transformação da primeira natureza em segunda natureza. A sociedade, majoritariamente, não assimilou a ótica sustentável do espaço planejado e ordenado no Zoneamento, e ainda hoje apresenta muita resistência à preservação ambiental, sendo frequentes as argumentações contrárias às inúmeras áreas protegidas.

\section{Frentes pioneiras e a gestão do território na região de Porto Velho}

Em 1991 (Gráfico 2), a taxa de desmatamento em Rondônia correspondia a 15\% da área territorial. Em 2000 cresceu para 24\%, e em 2010 representava 34\% (IBGE). Dados do GTA-RO e do IMAZON já indicavam, em 2007, uma área desmatada de 38\% de Rondônia. O que provocou a expansão do desmatamento quando, desde 1991, o Estado de Rondônia implantou a política de ordenamento do território, através da $1^{\text {a }}$ Aproximação do ZSEE? Dentre as respostas possíveis e relacionáveis apontamos que o crescimento da pecuária e a formação da região do agronegócio da soja, a partir de 1997, provocou uma corrida por novas terras, valorizando as áreas rurais do centro-sul de Rondônia e expandido novas frentes pioneiras, notadamente para as regiões dos municípios de Porto Velho, Nova Mamoré e Ariquemes, localizados no norte/noroeste do estado de Rondônia (Droulers, Le Tourneau y Machado, 2001; Silva 2013). 
Mapa 2: Rondônia: variação do rebanho bovino (1990-2011)

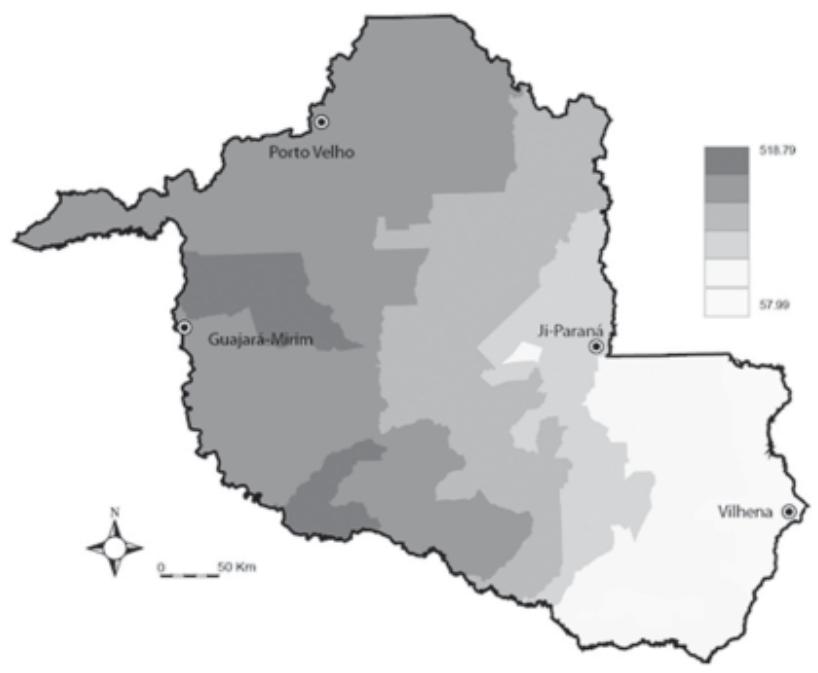

Fonte: Silva (2013). Elaborado com Philcarto - )

Em 1990, o efetivo bovino era de 943.256 cabeças, em 2000 representava 4.178.316, e aumentou para 9.684.055 cabeças em 2011, crescendo 10 vezes nesse período. Contudo, se nos anos iniciais a pecuária se concentrava no centro-sul de Rondônia o avanço dos grãos (soja e milho) deslocou o rebanho bovino principalmente para o norte e noroeste do Estado, na região de Porto Velho, ainda que se registre que a pecuária cresceu em todas as sub-regiões, tornando-se a principal mercadoria do campo rondoniense (Mapa 02). Analisamos o processo de expansão da pecuária em Rondônia, explanando as seguintes questões:

“A movimentação geográfica do rebanho bovino, no período de 11 anos, demonstra diferenças abissais no uso do território, ressaltando que no sul rondoniense essa atividade continua importante, mas cede cada vez mais espaço à atividade agrícola dos grãos. O deslocamento gradual, que varia de 58 a 518\%, movimenta-se para áreas ainda pouco ocupadas, objeto de grilagem de terras, desmatamentos em Unidades de Conservação e conflitos agrários (pela terra e madeira), que opõem agentes territoriais socialmente diferentes, mas que perseguem objetivos comuns, qual seja, transformar a natureza em espaço da agricultura. As forças do capital agropecuário expandem-se territorialmente, cuja tensão social se cristaliza na transformação de áreas antes preservadas, onde a floresta era um elemento presente na paisagem, por conseguinte, com pouco desmatamento, em áreas de expansão da pecuária extensiva e de 
extração madeireira. A concentração geográfica da modernização conservadora da agricultura no sul rondoniense desloca novas frentes pioneiras em busca de terras, convertendo áreas de floresta em pastagens. Isso tem rebatimentos na política estadual de ordenamento do território, seja no aumento do desmatamento, na pressão para redução de Unidades de Conservação, ou estimulando a invasão dessas áreas protegidas. A modernização da agricultura repõe a pauta da questão territorial que demanda a produção de novos territórios do agronegócio, frequentemente em conflitos com territórios culturais e das populações tradicionais da Amazôni” (Silva, 2013: 78-79).

Como afirmamos, as dinâmicas territoriais do espaço rural em Rondônia se fundamentaram na conversão do meio natural para o meio técnico e, atualmente, se manifesta pontualmente como meio técnico-científico informacional (Santos, 1996), provocado pela emergência da agropecuária científica globalizada produtora de commodities, das quais se destacam a soja e a carne bovina (Silva, 2015). A capitalização dos agentes territoriais especialmente grandes agricultores, fazendeiros/pecuaristas, madeireiros e centenas de famílias camponesas - em geral migrantes das regiões central e sul de Rondônia formaram a nova frente pioneira ${ }^{14}$ que se desloca para novas áreas rurais sob o controle do Estado ou às terras que estão com problemas de regularização fundiária e de definição de posse ${ }^{15}$.

A expressão geográfica que mais cristaliza as contradições na perspectiva da gestão e do ordenamento territorial em Rondônia são as novas vilas e povoados rurais que surgem em meio à floresta, seja nos limites ou mesmo dentro das Unidades de Conservação. Trata-se de um processo geograficamente produzido que ignora os mecanismos de gestão do território, ao mesmo tempo em que demonstra, inequivocamente, a fragilidade institucional na defesa da preservação e conservação ambiental. Indica, portanto, a negação dos grupos sociais e econômicos em aceitar a definição de territórios destinados à sustentabilidade ambiental.

Essa é a geografia configurada no município de Porto Velho a partir do ano 2000, com o surgimento do povoado de União Bandeirantes (Figura 2), classificado pelo IBGE (2010) como aglomerado rural ${ }^{16}$. O povoado está localizado no Distrito de Mutum-Paraná, nos limites da Reserva Extrativista Jaci-Paraná e Terra Indígena Karipunas. O acesso se faz através da rodovia BR-364, sentido Acre, e a estrada Linha 101, ficando a uma distância de 160 km da cidade de Porto Velho, capital do Estado de Rondônia. A vila e sua área rural estão localizadas na Subzona 2.1 do ZSEE, cujas diretrizes institucionais recomenda que seja "priorizado o aproveitamento dos recursos naturais, mantendo as atividades agropecuárias existentes, sem estímulo a sua expansão, fomentando as atividades de manejo florestal e do extrativismo, do ecoturismo e da pesca em suas diversas modalidades” (Rondônia, 2010:16). Ou seja, sob a orientação do ordenamento territorial deveria na região de União Bandeirantes desenvolver o aproveitamento das potencialidades naturais, principalmente na economia madeireira, 
através do incentivo do manejo florestal e outras atividades produtivas ambientalmente sustentáveis.

\section{Figura 2: União Bandeirantes e áreas protegidas (Unidades de Conservação e Terras Indígenas) - 2005.}

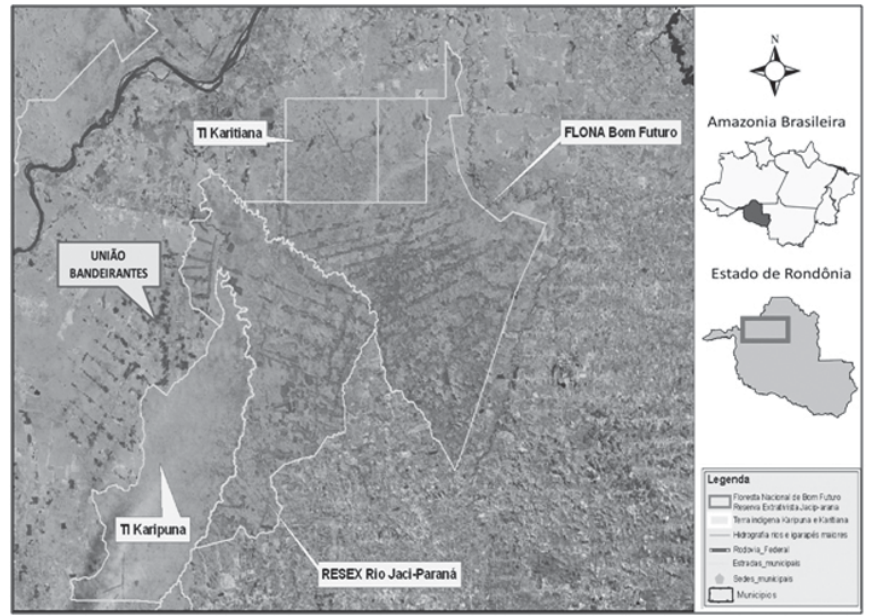

Fonte: SIPAM, 2007.

A ocupação espontânea que ocorre em diversas regiões de Rondônia avançou para o espaço rural de Porto Velho, ocupando terras em disputa jurídica em termos de definição de propriedade. Nessa situação, dezenas de famílias, em geral camponesas, ocuparam e recortaram uma área que deu origem ao povoado de União Bandeirantes. Nesse processo, agregaram-se pecuaristas e, principalmente, as empresas madeireiras que fizeram a pilhagem ambiental, produzindo o desmatamento numa região que há quinze anos não se tinha essa problemática. A migração camponesa oriunda, em geral, das regiões central e sul de Rondônia, consistiu em nova onda migratória, sendo que algumas dessas famílias vivenciaram o segundo e mesmo o terceiro processo migratório em Rondônia, o que indica a problemática da permanência na terra em função, sobretudo, da expansão do agronegócio. Na realização de pesquisas de campo verificamos o fluxo migratório, observando a quantidade de famílias que chegavam diariamente na vila, em geral, para comprar terras.

As irregularidades e o passivo ambiental em União Bandeirantes obrigaram os agentes políticos e grupos sociais local a se mobilizarem no sentido de assegurar a permanência da população nessa área, assim como a presença dos madeireiros, pecuaristas e grileiros de terras públicas. A 
resposta uma vez mais foi (des)configurar o ordenamento territorial, promovendo alterações legais no Zoneamento para ajustá-lo às demandas agrárias e territoriais postas pelo surgimento de União Bandeirantes (Figura 3). A Assembleia Legislativa do Estado aprovou a Lei Complementar $n^{0}$ 308 de 09/11/2004, "transformando áreas ocupadas irregularmente sob o comando de madeireiros e grileiros em zona agropecuária (subzona 1.3), também sem estudos ou critérios transparentes” (GTA/RO 2008: 19). Foi dessa forma que o povoado "mudou" de diretriz em termos do ordenamento do território no âmbito do Zoneamento. O uso do território foi consideravelmente alterado, incorporando atividades da agropecuária e extração madeireira que, por conseguinte, legalizou os crimes ambientais.

\section{Figura 3: Vila de União Bandeirantes, município de Porto Velho/ Rondônia (2014). \\ Foto A: área central (2012); Foto B: obras de infraestrutura e asfaltamento da rua principal (2014).}

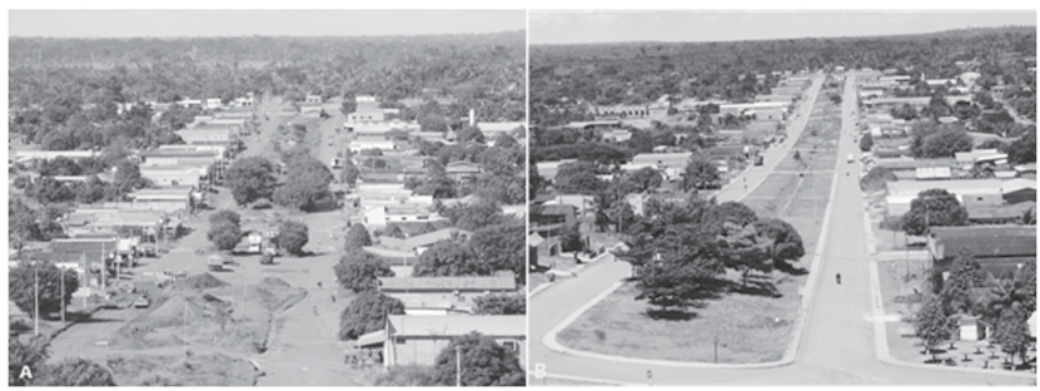

Fonte: Autor

O crescimento populacional se torna outra variável relevante para entendermos essas transformações geográficas. Os dados são díspares, o que reforça a intensidade do fluxo migratório e a consequente conversão das áreas naturais em espaço da agropecuária. O levantamento do Censo Demográfico de 2010 indicou uma população de 8.000 habitantes em União Bandeirantes, enquanto que a EMATER/RO ${ }^{17}$ informa que esses números equivalem a 18.000 habitantes, sendo 10.000 na vila e 8.000 na área rural, distribuídos em 875 propriedades rurais, em sua maioria concentrada nos estratos fundiários inferior a 100 hectares, indicando a forte presença do campesinato, mas também a formação de grandes fazendas (EMATER/RO 2012). Devemos considerar que esses dados podem ser maiores, visto a intensidade do fluxo migratório e da expansão agropecuária.

Em poucos anos a produção agropecuária de União Bandeirantes assumiu grande relevância na geografia de Porto Velho, fornecendo diversos produtos agrícolas (café, milho, feijão, mandioca, cacau). Mas a pecuária 
assume relevo na paisagem e se consolida como a principal atividade produtiva. São 940 propriedades que desenvolvem a atividade pecuária com 82.766 bovinos, sendo 59\% destinado à produção de carnes (rebanho de corte) e $41 \%$ referente ao gado leiteiro, com produção aproximada de 20.000 litros de leite/dia. Em decorrência da transformação do espaço natural para um espaço técnico, este cristalizado na agropecuária e extração madeireira, os indicadores de desmatamentos igualmente são alarmantes, chegando a uma taxa de 58,69\% para uma área de 120.064,4983 hectares, numa região que no ano de 1999 não havia registro considerável de desflorestamento.

O povoado de União Bandeirantes indica o surgimento das frentes pioneiras que pressionam Unidades de Conservação e Terras Indígenas e, consequentemente, impactam ambientalmente esses lugares, mas, sobretudo, os territórios das populações indígenas e dos seringueiros que resistem ao avanço do capital no espaço rural. Temos o encontro conflituoso entre duas lógicas de se produzir o espaço regional a partir do ordenamento territorial. $\mathrm{O}$ encontro entre a modernidade capitalista que transforma a floresta em pastagem, e o território dos povos da floresta, que vivenciam as mudanças da sociedade derivada da colonização agrícola, que tende a mercantilizar a natureza e os territórios culturais protegidos no âmbito do ZSEE.

\section{Considerações finais}

Ao término desse artigo foi publicada, na mídia regional, a notícia referente à liminar concedida pelo Superior Tribunal de Justiça (STJ) que, atendendo medida jurídica impetrada pelo Ministério Público Federal (MPF), manteve "os efeitos da decisão que proibiu a prática de mineração no entorno e na área da Reserva Indígena Roosevelt, em Rondônia, terra do povo Cinta Larga"18. A área do entorno da reserva indígena, segundo estudos, é considerada uma das maiores minas de diamantes do mundo, atraindo a exploração ilegal feitapor garimpeiros e, principalmente, por empresas e grupos econômicos que atuam politicamente no Congresso Nacional visando rever a norma constitucional que proíbe a exploração mineral em terras indígenas. Os conflitos entre invasores (garimpeiros e empresas) e os indígenas já ocorriam, mas a lentidão dos órgãos públicos responsáveis em controlar o processo, indiretamente, determinou a eclosão do conflito em abril de 2004, quando 29 garimpeiros foram mortos dentro da área indígena.

Nesse período, o ZSEE de Rondônia já estava amplamente divulgado e incorporado nas decisões dos órgãos públicos. Contudo, as diversas esferas administrativas dos entes federados ainda apresentam divergências quanto à sustentabilidade ambiental em termos de ordenamento territorial. No âmbito dos órgãos federais há graves dissensões em relação à gestão do território (há conflitos entre o INCRA, FUNAI, DNPM, IBAMA/ICMBIO, por exemplo), situação que se repete na esfera estadual em que o Governo de Rondônia ao mesmo tempo em que institui Unidades de Conservação, 
não aplica os instrumentos normativos para que essas áreas protegidas possam efetivamente cumprir o seu papel no âmbito do ordenamento territorial.

A formação sócio-espacial de Rondônia a partir do processo de colonização se consolida com a expansão agropecuária e madeireira, aglutinando um conjunto de forças políticas que, mesmo contraditórias, defendem um eixo desenvolvimentista que contrasta com as políticas de sustentabilidade ambiental (preservação, conservação e uso sustentável do território). O Zoneamento se tornou o principal instrumento de gestão do território em Rondônia, mas sua realização se deveu às exigências e pressões do Banco Mundial e, posteriormente, da sociedade civil organizada. Contudo, dado a relação histórica da maioria da sociedade rondoniense formada no processo de colonização, que opôs homem e natureza no âmbito das suas representações sociais, o sentido do território perpassa a sua leitura como recurso, como espaço destinado à reprodução social baseada na exploração da natureza em seu permanente processo de mercantilização.

Ao tempo que o ZSEE é comemorado na propaganda governamental como o primeiro da Amazônia legal, exibindo certo orgulho e ufanismo institucional, o que se verifica ao longo de duas décadas (1998 a 2008) são os constantes processos de supressão das áreas institucionais destinadas à preservação e conservação ambiental, assim como, as áreas que servem de “escudo” aos povos da floresta, em especial, os indígenas, os seringueiros e os quilombolas, populações que vivenciam cotidianamente a pressão da sociedade envolvente para com seus territórios. O caso mais eloquente ocorre na região de Porto Velho, com a formação de União Bandeirantes, um povoado rural inscrito em meio à floresta, sob a negligência dos órgãos públicos, mas com apoio dos grupos políticos e econômicos que hegemonizam o controle do Estado e que dilaceram o ordenamento do território.

Na ciência geográfica a categoria de análise território expressa a espacialidade do poder, processos que revelam territorialidades em disputas, ou seja, projetos e ideias dos grupos e das classes sociais em permanente devir histórico para produzir o espaço, este sempre sendo um campo de reprodução social. No caso de Rondônia, há ações sistemáticas instituídas no Estado, sob intensa pressão do bloco político-territorial formado na aliança dos grupos econômicos, em reduzir o território e a vida - portanto, as territorialidades - dos povos que habitavam a região antes do avanço do capital no espaço agrário rondoniense. 


\section{Notas}

${ }^{1}$ O presente artigo resulta dos seguintes Projetos de Pesquisa: "Dinâmicas Territoriais do Agronegócio e da Agricultura Camponesa em Rondônia” (Programa Santander Universidades/Unir), e “Globalização e Espaço Agrário em Rondônia” (UNIR/CNPq/ 2015-2016).

${ }^{2}$ O Instituto Nacional de Colonização e Reforma Agrária (INCRA) foi criado através do Decreto Lei $n^{\circ} 1.110$ de 09/07/1970. É responsável pelas políticas de assentamentos rurais, reforma agrária e regularização fundiária. Nas décadas de 1970 a 1990, o INCRA teve grande influência na gestão do território em Rondônia em função do controle das terras federais, criando verdadeiros territórios a partir dos inúmeros projetos de assentamento rural.

${ }^{3}$ É certo que há registro de vários conflitos com os indígenas antes mesmo da construção da Estrada de Ferro Madeira Mamoré, no início de século XX. Contudo, somente a partir da colonização é que as questões do território e das territorialidades assumem relevo no conjunto social que, dado o intenso processo de transformação da natureza em recursos da sociabilidade capitalista, causou inúmeros conflitos e estranhamentos com as populações tradicionais da Amazônia (indígenas, seringueiros, caboclos, ribeirinhos, quilombolas).

${ }^{4}$ Programa de Desenvolvimento Integrado no Noroeste do Brasil - POLONOROESTE foi criado através do Decreto n $^{\circ} 86.029$ de 27.05.81 e sua execução finalizou em 1987.

${ }^{5}$ Formulado por Milton Santos e Ana Clara Torres Ribeiro na década de 1970, o conceito de região concentradaexpressa a formação de um espaço contínuo, abrangendo os estados do Sul e do Sudeste do Brasil, com alta densidade técnica e científica incorporada ao território, decorrente das mudanças econômicas e sociais nessas regiões. Na obra Brasil:Território e Sociedade... Santos e Silveira (2001) articulam esse conceito para o entendimento do território usado, apontando para densidade da produção, a circulação das mercadorias, serviços tecnológicos e financeiros intensos, centralizados pelas metrópoles de São Paulo, que mantém a primazia urbana, e do Rio de Janeiro, formando um espaço contínuo que se expressa no meio técnicocientífico-informacional. Alguns estudos apontam a incorporação do Mato Grosso do Sul, Mato Grosso e Goiás à região concentrada, em função da intensidade do desenvolvimento do agronegócio (carnes, cana e grãos) e das transformações territoriais impostas pela dinâmica multiescalar dessas atividades produtivas (Silva, 2014).

${ }^{6}$ Instituto Brasileiro de Desenvolvimento Florestal (IBDF), transformado no Instituto Brasileiro do Meio Ambiente e dos Recursos Naturais Renováveis (IBAMA); Fundação Nacional do Índio (FUNAI).

${ }^{7}$ O Território Federal de Rondônia passou a categoria de Estado da Federação através da Lei Complementar $n^{0} 41$ de 22/12/1981. O processo de colonização iniciado na década de 1970 e o forte fluxo migratório contribuíram para essa mudança jurídica, que no campo político requeria um Governo mais presente das demandas locais, atendendo uma classe política emergente que, posteriormente, governaria, desde 1994, o Estado de Rondônia. Na condição de Território a gestão estava sob o comando de Brasília (Governo Federal), ao passo que na categoria Estado as elites política e econômica local assumiam o controle da gestão, implantando seus diversos projetos, inclusive, 
suas concepções de espaço e território.

${ }^{8}$ Decreto Estadual $n^{\circ} 3.782$ de 14/06/1988, posteriormente ratificado através da Lei Complementar $\mathrm{n}^{0} 52$ de 20/12/1991. Cabe ressaltar que o Banco Mundial pressionou o Governo de Rondônia a validar e publicar a $1^{\text {a }}$ Aproximação do Zoneamento, condicionando a aprovação do PLANAFLORO em função desse instrumento de gestão do território, daí a demora entre 1988 e 1991.

${ }^{9}$ Dentre as críticas, destacam-se: na ótica do Governo a primeira aproximação do ZSEE foi tratada como um trabalho eminentemente técnico; limitações de dados primários; visão utilitária dos recursos naturais; a escala cartográfica 1: 1.000 .000 foi considerando inadequada para fins de planejamento e execução de políticas públicas; ingerências políticas de setores empresariais e políticos que descaracterizavam a proposta e sua concepção; ausência de participação da sociedade civil (FORUM, 1997: 83).

10 “O empréstimo do Banco Mundial para o Planafloro, no valor de US\$ 167 milhões, foi aprovado pelos diretores executivos em março de 1992. A assinatura dos acordos contratuais ocorreu em setembro de 1992. O Banco declarou a efetividade do empréstimo, com um prazo inicial de quatro anos, em janeiro de 1993 e os primeiros desembolsos se iniciaram em junho daquele ano” (GTA/RO, 2009: 14).

${ }^{11} \mathrm{O}$ consórcio vencedor foi formado pelas empresas Tecnosolo/DHV/Eptisa, cujo contrato foi no valor de US\$19,5 milhões, muito superior à estimativa inicial de US\$ 11, 4 milhões.

12 SEDAM: Secretaria de Estado do Desenvolvimento Ambiental; ITERON: Instituto de Terras do Estado de Rondônia; INCRA: Instituto Nacional de Colonização e Reforma Agrária; FUNAI: Fundação Nacional do Índio; IBAMA: Instituto Brasileiro do Meio Ambiente.

${ }^{13}$ A segunda aproximação do ZSEE foi instituída pela Lei Complementar $n^{\circ} 233$ de 06/ $06 / 2000$.

14 Trata-se de um conceito formulados por geógrafos para caracterizar expansão espacial da sociedade e da economia em terras ainda pouco aproveitadas no Brasil. Nesse processo se destaca a construção da sociabilidade capitalista, representada na transformação da terra em mercadoria e o retalhamento desta para os colonos expropriados, através dos mecanismos de aquisição e distribuição de terras. Desse modo, tem-se a inserção das relações capitalistas vinculadas à construção social da mercadoria e uma forma de produção e organização do espaço geográfico (Thery 2012; Silva 2012; 2015).

${ }^{15}$ A regularização fundiária é uma questão central relacionada a posses e conflitos agrários na Amazônia. Através do Programa Terra Legal Amazônia, o Governo Federal pretende legalizar as propriedades dos camponeses e diminuir os conflitos agrários na região. O programa busca regularizar áreas da União de até 15 módulos fiscais ocupados por posseiros nos nove estados da Amazônia Legal, e pretende entregar títulos de terras a cerca de 300 mil posseiros que ocupam terras públicas federais não destinadas. O objetivo com a segurança jurídica é reduzir os conflitos e a grilagem de terras.

${ }^{16}$ Segundo o IBGE (2010: 19-21), define-se aglomerado rural como uma "localidade 
situada em área legalmente rural, onde existam unidades domiciliares que conformem um conjunto de edificações adjacentes (50m ou menos de distância entre si) com características de permanência”. [São classificados como rural do tipo extensão urbano, povoado e núcleo]. Povoado - é um aglomerado rural sem caráter privado ou empresarial, ou seja, não vinculado a um único proprietário do solo (empresa agrícola, indústrias, usinas, etc.), cujos moradores exercem atividades econômicas, quer primárias (extrativismo vegetal, animal e mineral; e atividades agropecuárias), terciárias (equipamentos e serviços) ou, mesmo, secundárias (industriais em geral), no próprio aglomerado ou fora dele. O povoado é caracterizado pela existência de um número mínimo de serviços ou equipamentos para atender aos moradores do próprio aglomerado ou de áreas rurais próximas.

${ }^{17}$ Empresa que presta o serviço de assistência técnica e extensão rural para o Governo do Estado de Rondônia.

${ }^{18}$ Site de notícias do jornal eletrônico Tudorondonia: http://www.tudorondonia.com/ noticias/liminar-proibe-extracao-de-diamantes-na-reserva-indigena-roosevelt-e-emseu-entorno-,46045.shtml, acessado em 29/07/2014. 


\section{Bibliografia}

Becker, B. (1991), “Geografia Política e Gestão no Limiar do Século XXI: Uma Representação a partir do Brasil”. Revista Brasileira de Geografia, v. 53, n. 3, p.169-182.

Becker, B., y Egler, C. (1997), Detalhamento da metodologia para execução do zoneamento ecológico-econômico pelos Estados da Amazônia Legal. Ministério do Meio Ambiente, dos Recursos Hídricos e da Amazônia Legal / Secretaria de Assuntos Estratégicos da Presidência da República, Brasília.

Costa, W. M. (1991), O Estado e as Políticas Territoriais no Brasil. Contexto, São Paulo.

Coy, M. (1987), “Rondônia: frente pioneira e programa POLONOROESTE. O processo de diferenciação sócio-econômica na periferia e os limites do planejamento público”. Tübinger Geographische Studien, n. 95, p. 253270.

Davidovich, F. (1991), “Gestão do Território: Um tema em questão”, Revista Brasileira de Geografia, v. 53, n. 3, pp.7-31.

Droulers, M.; Le Tourneau. F. M; Machado, L. (2001), “Conflits d’usage de l'espace au Rondônia (Amazonie brésilienne)”, Cybergeo : European Journal of Geography [En línea], Política, Cultura, Representaciones, documento 194, Publicado El 21 agosto 2001. http://cybergeo.revues.org/3772

EMATER-RO. (2012), Associação de Assistência Técnica e Extensão Rural do Estado de Rondônia, Plano de desenvolvimento sustentável da agricultura familiar do Distrito de União Bandeirantes-RO. Julho, 21 p., Porto Velho.

FORUM. (1997), Fórum das Organizações Não-Governamentais que atuam em Rondônia. Políticas públicas e desenvolvimento sustentável em Rondônia: problemáticas e desafios para sua implementação. 154 p., Porto Velho,

GTA/RO. (2008), Grupo de Trabalho Amazônico/Regional Rondônia. O fim da floresta? A devastação das unidades de conservação e terras indígenas no Estado de Rondônia. 60 p. Junho, Porto Velho.

Haesbaert, R. (2004), O mito da desterritorialização: do "fim dos territórios” à multiterritorialidade. Bertrand Brasil, Rio de Janeiro.

IBGE (2006), Censo Agropecuário - 2006: Brasil, grandes regiões e unidades da federação, Rio de Janeiro.

IBGE (2011), Sinopse do Censo Demográfico 2010, Rio de Janeiro. 
INCRA. (2013), Superintendência Regional de Rondônia (SR-17/RO), Informações Gerais - Projetos de Assentamento e Colonização/Consolidado, Porto Velho.

Moraes, A. C. R. (1994), Meio Ambiente e Ciências Humanas. Hucitec, São Paulo.

Nunes, D. (1997), “Desmatamento e Unidades de Conservação em Rondônia”. Presença, v. 10, p. 52-61.

Oliveira, J. L. (2010), Rondônia: geopolítica e estrutura fundiária. Grafiel, 1 ed., Porto Velho.

Pedlowski, M.; Dale, V.; Matricardi, E. (1999), “A criação de áreas protegidas e os limites da conservação ambiental em Rondônia”, Ambiente e Sociedade, p. 93-107.

Raffestin, C. (1993), Por uma Geografia do Poder, Ática, São Paulo.

Ribeiro, B.; Veríssimo, A.; Pereira, K. (2005), O avanço do desmatamento sobre as áreas protegidas em Rondônia, Imazon, Belém.

RONDONIA (2010). Governo do Estado de Rondônia. Secretaria de Estado do Desenvolvimento Ambiental. 21 anos de Zoneamento Socioeconômico e ecológico do Estado de Rondônia: planejamento para o desenvolvimento sustentável e proteção ambiental, SEDAM, Porto Velho.

Santos, M. (1996), A natureza do espaço: técnica e tempo, razão e emoção, Hucitec, São Paulo.

Silva, R. G. (2015), “Amazônia globalizada: da fronteira agrícola ao território do agronegócio - o exemplo de Rondônia”. Confins [Online], 23, posto online no dia 01 Março 2015, http://confins.revues.org/9949

Ídem. (2014), “Espaço, sociedade e natureza em Rondônia”. Revista GeoAmazônia, n. 2, v. 01, p. 144 - 165. Disponível: http:// www.geoamazonia.net/index.php/revista/article/view/26/pdf_25

Ídem (2013), “Globalização, agricultura e a formação do meio técnicocientífico-informacional em Rondônia”. ACTA Geográfica, v.7, n.15, p. 69-83. Disponível: http://revista.ufrr.br/index.php/actageo/article/view/ $1383 / 1211$

Ídem (2012), "Das margens do Madeira ao interior da floresta: percursos da formação sócioespacial de Rondônia (1970-1995) ”. In: Almeida Silva, A; Nascimento Silva, M. G. S; Silva, R. G. C. (Org.). Colonização, Território e Meio Ambiente em Rondônia: Reflexões geográficas. 1ed., Editora SK, p. 124, Curitiba. 
Polis, Revista Latinoamericana, Volumen 15, $N^{\circ}$ 45, 2016

SIPAM (2007). Sistema de Proteção da Amazônia. Centro Técnico Operacional de Porto Velho. Levantamento de informações de cobertura da terra: a situação no Estado de Rondônia em 2005. Palestra na Semana de Geografia da UNIR, Porto Velho.

Thery, H. ([1974] 2012), Rondônia: mutações de um território federal na Amazônia brasileira. SK Editores, Curitiba

Recibido: 30.03.15

Aceptado: 06.11.15 